\title{
Editorials
}

\section{When will J Soils and Sediments get assigned an Impact Factor?}

\author{
Henner Hollert \\ Department of Zoology, University of Heidelberg, Im Neuenheimer Feld 230, 69120 Heidelberg, Germany (Hollert@uni-heidelberg.de)
}

\section{DOI: http://dx.doi.org/10.1065/jss2006.11.191}

The 'Journal of Soils and Sediments - Protection, Risk Assessment, and Remediation' has been founded in 2001. JSS is the first journal entirely devoted to soils and sediments, hereby dealing not only with contaminated, but also with intact and disturbed soils and sediments. Recently, the two compartments soils and sediments have been extended by an intercompartment section, in order to reflect the need for a more holistic perspective: Rather than being distinct compartments, soils and sediments are intensively interlinked and thus soil and sediment scientists and managers should co-operate in order to solve the many existing problems which often occur at the interface of both media (Apitz 2005).

Because of the high quality of the published papers and of being the associated Journal of the European Sediment Network (SedNet) and International Union of Soil Science (IUSS), and the close connection to Environ Sci Poll Res (Hutzinger 2005) the 'Journal of Soils and Sediments' is highly recognized and cited. Additionally, the distribution of JSS by Springer publishers, resulting in more than 2000 institutional subscriptions in 40 countries, is an important issue concerning the excellent spread of the journal worldwide (Young \& Heinrich 2006).

However, because of the need of the scientific community to publish in journals with high impact factors, the question has frequently been raised "when will JSS be included in the JCR Journal Citation Report, having an impact factor"? Consequently, it is my pleasure to explain in the following when and how the first impact factor will be calculated.

The influence of a journal is measured through the journal impact factor. Journal impact factors are published annually in the 'Journal Citation Reports' (e.g. JCR 2005). The journal impact factor is obtained by relating the number of articles during two consecutive years and the number of times these papers are cited during the next (third) year. Thus it takes three years to calculate an impact factor!

The first step for getting an impact factor assigned is being covered in the ISI-Science Citation Index Expanded (ISI-SCIEx, also known as 'Web of Science' or 'Web of Knowledge'). The coverage of 'Journal of Soils and Sediments' started in January 2005. Consequently, the first impact factor for JSS will be calculated within the JCR - Journal Citation Report 2007, which will be published approx. in July 2008. In brief, ISI will calculate the citations in any journals (including JSS) covered by ISISCIEx and published in 2007, citing recent articles of JSS published in the years 2005 and 2006.
To illustrate this methodology and to elucidate the high acknowledgement of JSS in the environmental scientific community, a theoretical calculation of the 2006 impact factor of JSS based on analyses in ISI-SCIEx has been conducted in Table 1.

In this context, it is important to mention that the Impact Factor 2006 will include all 2006 issues of journals indexed in ISISCIEx. The indexing process is time consuming, consequently, the late 2006 issues of the citing journals (e.g. the December issues) will be added to ISI-SCIEx until March 2007. To extrapolate this, the recent impact factor of 2.308 can be increased by at least $0.25 \%$, resulting in a theoretical impact factor of 2.886 for the year 2006! When compared to the recent JCR 2005, JSS would be ranked as number 9 of 140 journals in the environmental sciences category and number 1 of 29 journals in the agriculture and soil science category. This calculation is very encouraging and demonstrates that JSS will start in the JCR 2007 directly as one of the top journals in the environmental field.

Beside the impact factor, the Journal Immediacy Index is worth mentioning, since this index "can provide a useful perspective for comparing journals specializing in cutting-edge research" (Thomson 2006), indicating how quickly articles are cited. The immediacy index is the average number of times, an article is cited in the very year it is published. This index is calculated by dividing the number of citations to articles published in a given year by the number of articles published in that year. Actually, the 2006 Journal Immediacy Index could be calculated as 1.378 (13 $3^{\text {th }}$ November, including the JSS November issue), resulting in an overall index for JSS of approx. 1.723, based on the assumption shown above. When compared with the Journal Immediacy Indices for 2005, JSS can be ranked as number 1 of 140 journals in the environmental section and as number 1 of 29 journals in the agriculture/soil science section, elucidating how quickly articles in JSS are cited. That is encouraging as well.

\section{References}

Apitz SE (2005): New and recent developments in soil and sediment management, policy and science. Do we need a Journal of Soils AND Sediments? J Soils Sediments 5 (3) 129-133

Hutzinger O (2005): Passing the baton: A new editor-in-chief and a new challenge. Environ Sci Poll Res 12 (6) 315-317

Young AL, Heinrich AB (2006): Round Table: Editors Meeting ESPR, JSS and Int J LCA. Heidelberg, 13-14 October, 2006. Environ Sci Poll Res 13 (6) 361

Thomson (2006): Help page of the JCR. <http://www.thomson.com/solutions/scientific/>

Table 1: Impact factor calculation for J Soils and Sediments 2006

\begin{tabular}{l|c|c|c|c}
\hline Cites to recent articles ${ }^{1}$ & $/$ & Number of recent articles ${ }^{2}$ & $=$ & Impact factor \\
\hline 157 & $/$ & 68 & $=$ & 2.308 \\
\hline
\end{tabular}
${ }^{1}$ Cites in ISI-SCIEx 2006 to JSS articles published in 2004 and $2005=172$ (on $13^{\text {th }}$ November, including the JSS November issue)

